\title{
Angiotensin Converting Enzyme and Trypsin Inhibition by Garcinia Cambogia Seeds Extract
}

\author{
M. Sudarshan ${ }^{1 *}$, P. Jyothibai ${ }^{2}$ \\ ${ }^{1,2}$ Department of Studies and Research in Biochemistry, Tumkur University, Tumkur, India \\ *Corresponding author: sudarshanm2021@gmail.com
}

\begin{abstract}
In this project work, Garcinia cambogia seeds extract was prepared and analysed for inhibitory studies. G. cambogia or the Malabar tamarind, commonly used as a food preservative, flavouring agent or food-bulking agent, and as a traditional remedy to treat constipation, piles, rheumatism, edema, irregular menstruation and intestinal parasites in many Asian countries. $G$. cambogia seeds solvents (Methanol, ethylacetate, petroleum ether and acetone) extract were prepared and pharmacological activities were analyzed such as antioxidant activity, ACE inhibitory and trypsin inhibitory activities. Among the extracts tested, methanolic extract of $G$. cambogia has shown potent antioxidant, angiotensin converting enzyme and trypsin inhibitory activities.
\end{abstract}

Keywords: Garcinia cambogia seeds ACE, Trypsin inhibition Antioxidant activity.

\section{Introduction}

Studies have shown that many of these antioxidant compounds possess anti-inflammatory, antiatherosclerotic, antitumor, antimutagenic, anticarcinogenic, antibacterial and antiviral activities. The ingestion of natural antioxidants will reduce the risk of cardiovascular disease, diabetes and other diseases of cancer associated with ageing. The natural plant based antioxidants play an important role in the maintenance of human health (Branen et al., 1975). Synthetic antioxidants such as butylated hydroxytoluene (BHT) and butylated hydroxyanisole (BHA) have been used as antioxidants since the beginning of this century. But restrictions on these antioxidants have been imposed because of the corcinogenecity of these compounds. (Lo liger, 1991). Thus, the interest in natural antioxidants has increased considerably.

Garcinia gummi-gutt (L.) Roxb. or the Malabar tamarind, commonly known by its previous scientific name Garcinia Cambogia, is native to Southeastern Asia. The fruit rind is commonly used as a food preservative, flavouring agent or food-bulking agent, and as a traditional remedy to treat constipation, piles, rheumatism, oedema, irregular menstruation and intestinal parasites in many Asian countries. Commercial products containing G. cambogia catapulted onto the market and have received considerable positive and negative media attention. Garcinia is the largest genus of the Clusiaceae family comprising of 390 species. These polygamous trees or shrubs are mainly distributed in tropical Asia, Polynesia and Africa. Garcinia gummi-gutta (L.) Roxb. is one of the most medicinally important members of the Clusiaceae family. It is a small or medium size tree of up to 12 $\mathrm{m}$ tall with a rounded crown and drooping branches. Garcinia cambogia has a limited native global distribution, being restricted to India, Nepal and Sri Lanka, but it has been introduced elsewhere where it is distributed in the subtropical region of Asia including China, Malaysia and the Philipines. These trees are found mainly in the semi-evergreen to evergreen forests of Southwest India, predominantly in the Western Ghats (Maharashtra, Karnataka, Kerala and Tamil Nadu). $G$. cambogia is an economically important spice tree valued for the sun-dried smoked rind which is widely used as a flavour condiment, especially in fish curries. It is also used as a substitute of Kokum butter and as a common additive to make meals more filling. The fruit rind is used medicinally to treat rheumatism and bowel complaints and it is employed as a purgative, hydragogue, anthelmintic and emetic. It is also used in veterinary medicine where a rinse is used to treat mouth diseases in cattle. The fruits are edible, but very acidic and are not generally eaten raw.

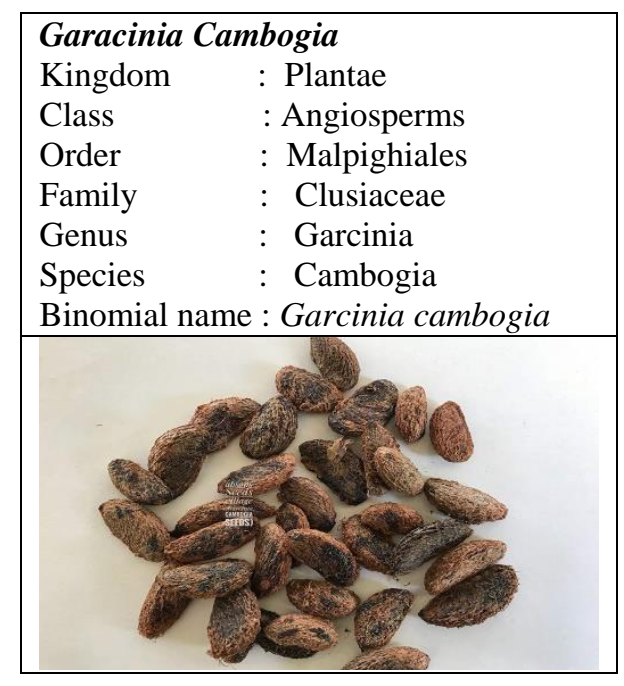

A tonic prepared from the fruit, which contains a high concentration of vitamin $\mathrm{C}$, is used in India to treat various heart diseases. G. cambogia is not only used medicinally; the rind is used to polish gold and silver ornaments and as a substitute for acetic acid for the coagulation of rubber latex, the gum is used 
as a varnish and the resin is used as a pigment in miniature paintings and water colors. In background of the above mentioned properties associated with G. cambogia seeds, this study has been taken up to evaluate scientifically the pharmacological properties of study the effect of solvent extract on antioxidant, ACE and trypsin activities.

\section{Methodology}

\section{A. Chemicals}

Porcine kidney used as angiotensin converting enzyme (ACE) source in this project was obtained from the local pork stall, Tumkur. Hippuryl-histidyl-leucine (HHL) acetate salt was purchased from Sigma-Aldrich Chemical Laboratories. All the other chemicals and reagents used in this study were of analytical grade.

\section{B. Partial purification of $A C E$}

\section{1) Preparation of porcine kidney acetone extract}

The porcine kidney acetone powder was prepared according to the method of Vermeirssen et al., (2002) with some modifications. The porcine kidney cortex was chopped into small pieces and suspended in chilled acetone for $30 \mathrm{~min}$. The cortex was homogenized with chilled acetone using conventional mixer grinder. Thus obtained homogenate was air dried and powdered. The acetone powder was dissolved in 100 $\mathrm{mM}$ phosphate buffer ( $\mathrm{pH} 8.3$ ) in the ratio of 1:10, stirred using magnetic stirrer overnight at $4^{\circ} \mathrm{C}$, centrifuged at $8000 \mathrm{rpm}$ for $20 \mathrm{~min}$. The supernatant obtained served as crude enzyme source of ACE and subjected to protein estimation.

2) Ammonium sulphate precipitation of crude enzyme

The crude enzyme extract $(45 \mathrm{~mL})$ was subjected to ammonium sulphate precipitation (20\% saturation), using magnetic stirrer, kept it in refrigerator overnight. Then centrifuged at $8000 \mathrm{rpm}$ for $20 \mathrm{~min}$. Precipitated protein is dissolved in $2 \mathrm{ml}$ of $10 \mathrm{mM}$ sodium phosphate buffer $(\mathrm{pH} 8.3$ ). Then the precipitated protein is dialysed using $12 \mathrm{kDa}$ cut off dialysis membrane against distilled water. Dialyzed sample was subjected to protein estimation and evaluated for the ACE activity.

\section{ACE assay}

ACE activity was measured by the spectrophotometric assay of Cushman \& Cheung (1971), with some modifications. This method is based on liberation of Hippuric acid (HA) from hippuryl -L- histidyl-L-leucine (HHL) catalysed by the ACE. (Chaudhary et al.,2013). The crude enzyme extract at different concentrations $(50,100 \mu \mathrm{l})$ with $150 \mu \mathrm{l} \mathrm{HHL}$ substrate $(8.3 \mathrm{mM})$ in $50 \mathrm{mM}$ sodium borate buffer (pH 8.3) containing $300 \mathrm{mM}$ $\mathrm{NaCl}$ incubated at $37{ }^{\circ} \mathrm{C}$ for 30 minutes. The reaction was terminated by the addition of $250 \mu \mathrm{L}$ of $1 \mathrm{M}$ HCL. To the resulting solution $1 \mathrm{ml}$ of ethyl acetate was added and centrifuged at $3000 \mathrm{rpm}$ for 10 minutes. HA, produced in the reaction mixture due to the hydrolysis of substrate catalysed by ACE is in the ethyl acetate upper layer. After that $0.5 \mathrm{ml}$ of ethyl acetate was taken out by a micropippet and transferred to a new test tube and heat evaporated to dryness by keeping in boiling water both. HA precipitated in the test tube was dissolved in 1 $\mathrm{ml}$ of distilled water. Absorbance of this solution was measured at $228 \mathrm{~nm}$ using an UV-Spectrophotometer.

The concentration of hippuric acid in the test reaction compared to control reaction was expressed as percentage of ACE activity. The activity of enzyme is expressed as nmoles of hippuric acid released $/ 30 \mathrm{~min} / \mathrm{mg}$ protein at $37{ }^{\circ} \mathrm{C}$ and the specific activity of enzyme is expressed as nmoles of hippuric acid released $/ \mathrm{min} / \mathrm{mg}$ protein at $37^{\circ} \mathrm{C}$. For inhibition studies, ACE is pre incubated with extracts for $30 \mathrm{~min}$ and assayed as mentioned above.

\section{Collection of the seeds}

The seeds of G. cambogia were purchased from local market and were grinded to fine powder form using mixie. The powder was used for further solvent extraction purpose.

\section{E. Solvent extraction}

G. cambogia seeds powder was extracted with petroleum ether, ethyl acetate, acetone and methanol using soxhlet apparatus. Each extract was concentrated in rotor evaporator. The extracts were dried and stored at $-20^{\circ} \mathrm{C}$ until further use.

\section{F. Trypsin inhibition study}

Trypsin inhibition was assayed in accordance with the method of Satake et al., 1963 by using casein (2\% in $200 \mathrm{mM}$ Tris- $\mathrm{HCl}$ buffer; $\mathrm{pH}$ 7.4) as the substrate. Briefly, different concentrations of plant extracts $(50-500 \mu \mathrm{g})$ are preincubated with trypsin at $37{ }^{\circ} \mathrm{C}$ for 30 minutes. Then all the reaction mixtures were incubated with $0.4 \mathrm{~mL}$ of casein solution at 37 ${ }^{\circ} \mathrm{C}$ for $2 \mathrm{~h}$. The reaction was stopped by adding $1.5 \mathrm{~mL}$ of 0.44 $\mathrm{M}$ Trichloroacetic acid and allowing the mixture to stand for 30 $\mathrm{min}$. The mixture was then centrifuged at 3,000 rpm for $5 \mathrm{~min}$. An aliquot $(1 \mathrm{~mL})$ of the supernatant was mixed with $2.5 \mathrm{~mL}$ of $0.4 \mathrm{M}$ sodium carbonate and $0.5 \mathrm{~mL}$ of $1: 2$ diluted $\mathrm{FC}$ reagent and incubated for $20 \mathrm{~min}$ at room temperature. The intensity of color developed in the reaction mixture was measured at 660 $\mathrm{nm}$. One unit of enzyme activity was defined as the amount of enzyme required to increase the absorbance by 0.01 at $660 \mathrm{~nm}$ in 1 min. Appropriate controls were maintained in all cases, and the results were expressed as percentage of inhibition.

Percentage of trypsin inhibition is calculated using fallowing equation.

Percentage of trypsin inhibition

$$
=\frac{\text { Control absorbance }- \text { sample absorbance }}{\text { Control absorbance } \mathrm{x} 100}
$$

\section{G. Antioxidant activity}

DPPH assay was carried out according to Sanja et al., 2009.In this method, different concentrations of test samples were diluted with 50\% Methanol and the volume was made upto $1 \mathrm{ml}$. 
Table 1

Partial purification of angiotensin converting enzyme

\begin{tabular}{|l|l|l|l|l|}
\hline & Protein concentration $(\mu \mathrm{g})$ & ACE activity* & Fold purity & \% yield \\
\hline Crude extract & 400 & 335 & - & - \\
\hline Ammonium sulphate precipitation & 50 & 670 & 200 & 25 \\
\hline
\end{tabular}

*nmoles of hippuric acid released $/ 30 \mathrm{~min} / \mathrm{mg}$ protein.

Then $140 \mu \mathrm{L}$ of $1 \mathrm{mM}$ DPPH solution was added to each test tube. DPPH diluted with methanol was taken as control. All the test tubes were incubated at room temperature for 30 minutes. Absorbance was taken at $520 \mathrm{~nm}$ in UV-visible spectrophotometer. The results are expressed as mean \% antiradical activity. The free radical scavenging activity was calculated using the following equation:

Percentage of antiradical activity

$$
=\frac{\text { Control absorbance }- \text { sample absorbance }}{\text { Control absorbance x } 100}
$$

\section{H. Protein estimation}

The protein content of test samples was estimated according to the method of Lowry et al., (1951) using bovine serum albumin (BSA) as standard.

\section{Results}

\section{A. Partial Purification of ACE}

In this project, ACE is partially purified by ammonium sulphate precipitation method. The kidney acetone powder was prepared by homogenizing kidney cortex using chilled acetone. The kidney acetone powder was dissolved in $300 \mathrm{mM}$ sodium borate buffer $(\mathrm{pH} 8.3)$ in the ratio of 1:10, centrifuged and supernatant served as crude enzyme. Further, the crude enzyme sample was subjected to ammonium sulphate precipitation (20\%). The precipitate was dialyzed to remove ammonium sulphate. The dialyzed fraction was subjected to protein estimation and evaluated for ACE activity. The dialyzed sample is considered as partially purified enzyme and used for inhibition studies. Crude sample of ACE had a protein concentration of $8 \mathrm{mg} / \mathrm{mL}$. Ammonium sulphate precipitate had a concentration of $1 \mathrm{mg} / \mathrm{mL}$. The specific activity, fold purity and yield are tabulated in table 1 .

\section{B. ACE assay}

ACE activity was assayed by using HHL as a substrate. Crude extract of porcine kidney has shown activity of 335 nmoles/30 minute/mg protein. Ammonium sulphate precipitate has shown a activity of $670 \mathrm{nmoles} / 30 \mathrm{~min} / \mathrm{mg}$ protein.

\section{Antioxidant activity}

The solvent extracts were evaluated for their antioxidant activity in vitro. The extracts showed differential antioxidant activity with varied $\mathrm{IC}_{50}$ values. Among the extracts tested, Methanol extract of G.cambogia exhibited a potent antioxidant activity with $\mathrm{IC}_{50}$ value of $20 \mu \mathrm{g} / \mathrm{mL}$ followed by ethyl acetate extract (Fig. 1).
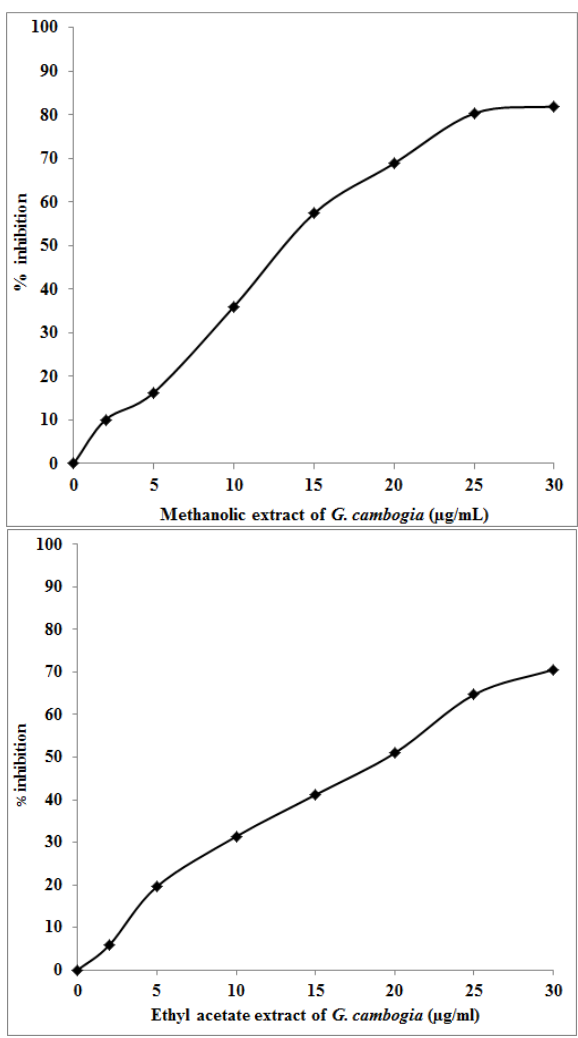

Fig. 1. DPPH radical scavenging activity of G. cambogia seeds extract. Values are average of three independent experiments. A) Methanolic extract B) Ethyl acetate extract

\section{ACE inhibition study}

ACE inhibition was done for all the solvent extract of $G$. cambogia seeds. But only methanolic extract showed inhibition of ACE activity. The inhibition was found to be dose dependent. The maximum inhibition of upto $76 \%$ was observed at a concentration of $500 \mu \mathrm{g}$ (Fig. 2).

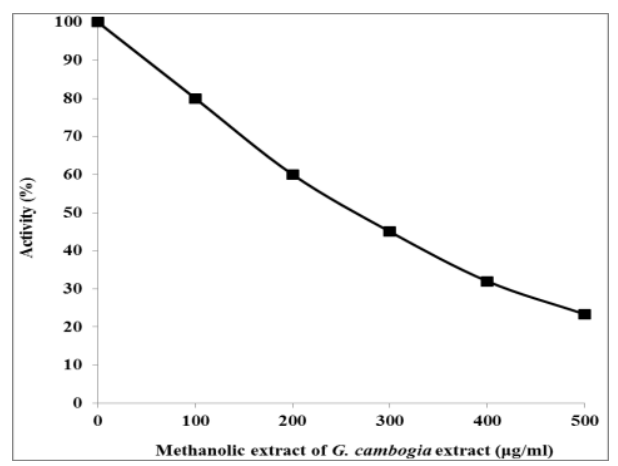

Fig. 2. Inhibition of angiotensin converting enzyme by methanolic extract of G. cambogia seeds. For inhibition study the ACE was preincubated with the extract for $30 \mathrm{~min}$ and analysed for activity using HHL as substrate.

Values are average of three independent experiments. Inhibition was expressed as activity in percentage 


\section{E. Trypsin inhibition assay}

Trypsin inhibition was done for all the extracts of $G$. cambogia. Among the four extracts, methanolic and ethylacetate extracts showed inhibitory property. Methanolic extract has shown potent trypsin inhibitory activity of $80 \%$, while the ethyl acetate extract showed $72 \%$ of inhibition (Fig. $3)$.
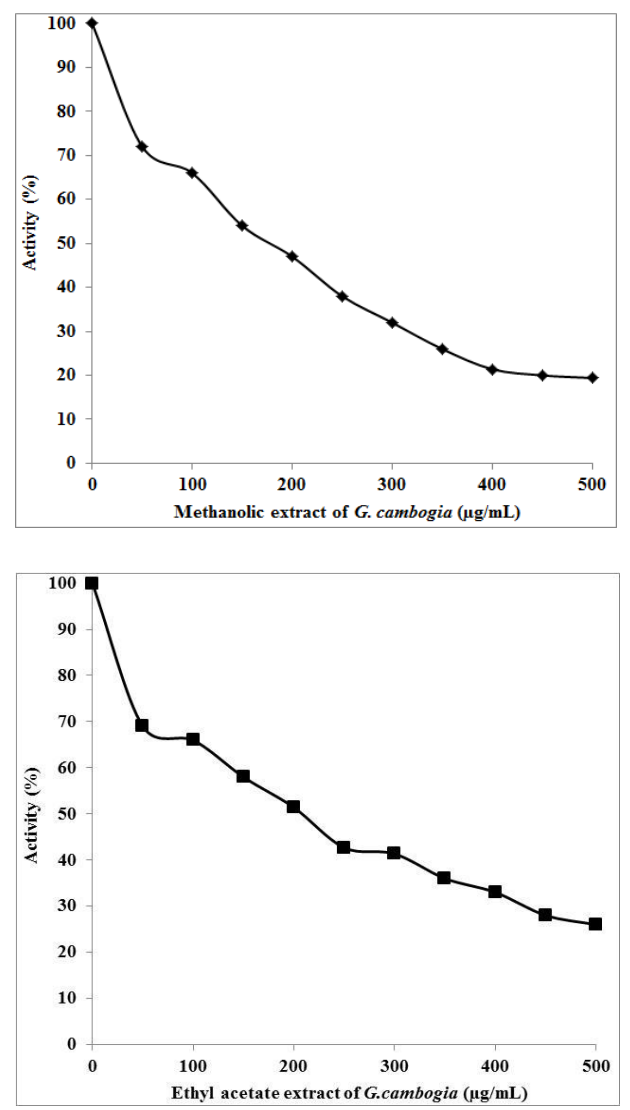

Fig. 3. Trypsin inhibitory activity of G.cambogia seeds extract. For inhibition studies trypsin is pre-incubated with extract for $30 \mathrm{~min}$. Then analysed for proteolytic activity as mentioned in the methodology section. A) Methanolic extract B) Ethyl acetate extract. The inhibition is expressed as \% activity

\section{Discussion and Conclusion}

In our project work ACE was partially purified from porcine kidney by employing ammonium sulphate precipitation technique. G. cambogia solvent extract have been prepared by Soxhlet extraction method. Later the samples were analyzed for antioxidant activity by DPPH method. Antioxidants are compounds which inhibit the oxidation by removing the free radical intermediates. Antioxidants are effective because they are willing to give up their own electrons to free radicals. After donating an electron an antioxidant becomes a free radical, in this state antioxidants are not harm full because they have the ability to accommodate the change in electrons without becoming reactive. The reduction in absorbance of DPPH because of decrease in its absorbance at $520 \mathrm{~nm}$ is induced by antioxidants. The decrease in absorbance of DPPH free radical is observed as the concentration of the sample increases. In this study the both the methanol and ethyl acetate extracts of G.cambogia showed prominent antioxidant activity. Further, $G$. cambogia was screened for trypsin inhibitory activity. The extracts were evaluated for their trypsin-inhibitory activity in vitro. Among the extracts tested, methanol extract has shown potent trypsin inhibitory activity (80\%) followed by ethyl acetate extract $(61 \%)$. Protease inhibitors, including trypsin inhibitors (TIs), are found in numerous organisms. Protease inhibitors isolated from plants have activities against insect larval growth, suggesting these proteins may play a role in defense. In humans, protease inhibitors are known to be essential for physiological regulation and have been associated with a range of diseases including neuropathic pain and skin desquamation. The extracts showed significant antioxidant activity and ACE and trypsin inhibitory activities in vitro. Among the four extracts, the methanol extract of the seeds showed the highest anti-oxidant activity with good ACE and trypsin inhibitory activities. Therefore, the methanolic extract of seeds has potent inhibitory molecule. Further isolation and characterization of the bioactive molecule will have great importance for pharmacological studies.

\section{References}

[1] Bram B, Mitchell K D, Fox J, Navar L G. 1993. Proximal tubular exretion of angiotensin Bram II in rats. Am. J. Physiol. 264(5), 891-898.

[2] Carey RM, Howell NL, Jin XH, Siragy HM. 2001. Angiotensin type 2 receptor-mediated hypotension in angiotensin type-1 receptor-blocked rats. Hypertension. 38(6):1272-1277.

[3] Cheung S, Wang L, Ondetti A, Sabo F, Cushman W. 1980. Binding of peptide substrates and inhibitors of angiotensin converting enzyme: Importance of the $\mathrm{COOH}$-terminal dipeptide sequence. J Biol Chem. 255(2):401-407.

[4] Coates D, Isaac RE, Cotton J, Siviter R, Williams TA, Shirras A, Corvol P, Dive V. 2000. Functional conservation of the active sites of human and Drosophila angiotensin Iconverting enzyme. Biochemistry. 39(30): 89638969.

[5] Deepak Kumar Semwal, Ilze Vermaak, Alvaro Viljoen R.B. Semwal et al. A comprehensive scientific overview of Garcinia cambogia. Fitoterapia. 102 (2015) 134-148.

[6] Ehlers MR, Riordan JF.1989. Angiotensin-converting enzyme: new concepts concerning its biological role. Biochemistry 28(13):5311-5318.

[7] Erdos EG. 1990. Angiotensin 1 converting enzyme and the changes in our concepts through the years. Lewis K. Dahl memorial lecture. Hypertension 16(4):363-370.

[8] Hoe SZ, Kamaruddin MY, Lam SK. 2007. Inhibition of angiotensinconverting enzyme activity by a partially purified fraction of Gynura procumbens in spontaneously hypertensive rats. Med Princ Pract. 16(3):203-208.

[9] Hooper NM, Turner AJ. 1987. Isolation of two differentially glycosylated forms of peptidyl-dipeptidase A (angiotensin converting enzyme) from pig brain: a reevaluation of their role in neuropeptide metabolism. Biochem J. 241(3):625-633.

[10] Loic Le Marchand. 2002. Biomed Pharmacother. 56, 296-301.

[11] Lowry OH, Rosenbrough NJ, Farr AL, Randall RJ. 1951. Protein measurement with Folin phenol reagent. J. Biol.Chem. 193(1): 265-275.

[12] Sanjay Biradar R, Bhagyashri D, Rachetti. 2013. American Extraction of some secondary metabolites \& thin layer chromatography from different parts of Centella asiatica L. American Journal of Life Sciences. 1(6), 243247.

[13] Satake, M., Murata, Y., Suzuki, T., 1963. Chromatographic separation and properties of three proteinases from Agkistrodon halys blomhoffii venom. J. Biochem. 53, 438-447. 
[14] Shi L, Mao C, Xu Z, Zhang L. 2010. Angiotensin-converting enzymes and drug discovery in cardiovascular diseases. Drug Discov Today. 15(910):332-341.

[15] Siddesha JM, Angaswamy N, Vishwanath BS. 2011. Phytochemical screening and evaluation of in vitro angiotensin converting enzyme inhibitory activity of Artocarpus altilis leaf. Nat Prod Res.

[16] Skeggs LT, Kahn JR, Shumway NP.1956. Preparation and function of the hypertensin converting enzyme. J Exp Med. 103(3):295-299.
[17] Turner AJ, Hooper NM. 2002. The angiotensin-converting enzyme gene family: genomics and pharmacology. Trends Pharmacol Sci. 23(4):177183.

[18] Vermeirssen V, Augustijns P, Morel N, Van Camp J, Opsomer A, Verstraete W. 2005. In vitro intestinal transport and antihypertensive activity of ACE inhibitory pea and whey digests. Int J Food Sci Nutr. 56(6):415-430. 